\title{
El Ángel de la prehistoria: anacronismo, discontinuidad y huella en la facies inconsciente de la historia
}

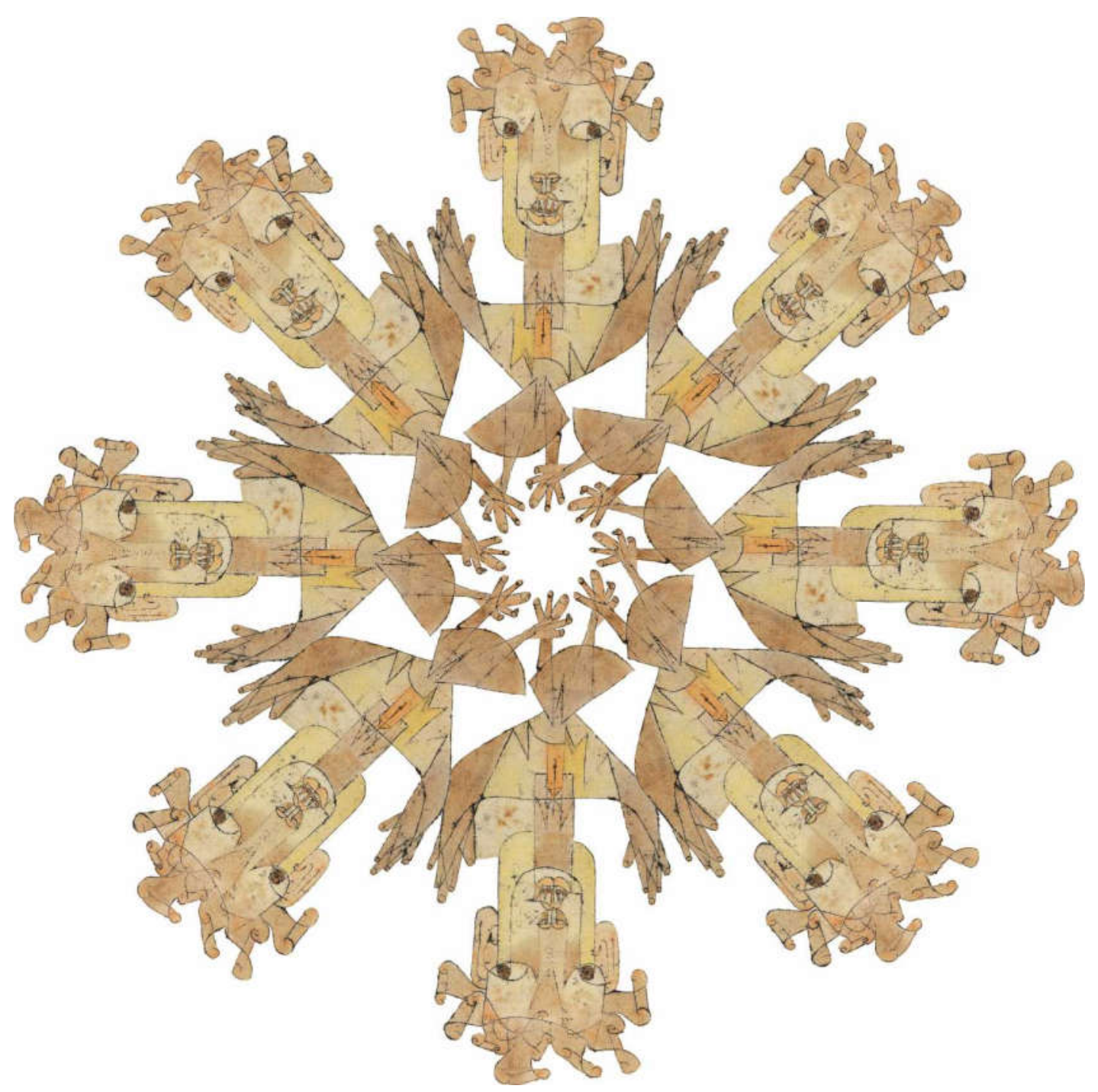

Angelus Novus. Paul Klee, 1920, fotografia (detalhe).

\section{Francisco Naishtat}

Doutor em Filosofia pela Universidad de Buenos Aires (UBA). Professor da Facultad de Ciencias Sociales da UBA. Pesquisador do Conicet. Autor, entre outros livros, de L'action et le langage. Paris: L'Harmattan, 2010. fnaishtat@gmail.com 


\section{El Ángel de la prehistoria: anacronismo, discontinuidad y huella en la facies inconsciente de la historia}

The Angel of prehistory: anachronism, discontinuity and trace in the unconscious facies of history

\section{Francisco Naishtat}

\section{RESUMEN}

Según la primera generación de la École des Annales, el anacronismo es "el más imperdonable de todos los pecados". Sin embargo, Benjamin acentuó no sólo cierta inevitabilidad del anacronismo, sino inclusive su potencialidad. Su noción de huella (Spur) destaca aquello que persiste a través de diferentes épocas, comprendido a partir de una idea de pervivencia (Nachleben), que da lugar a la figura arqueológica de un pasado que interrumpe la relación del presente consigo mismo. El trabajo de Didi-Huberman, dando cauce a las intuiciones señaladas por Benjamin, hace de la potencia del anacronismo el punto de partida para la conceptualización de una metodología en el ámbito de la historia. La inactualidad del pasado reviste carácter de incumplido, prehistórico, arqueológico, discontinuo e inconsciente, cuya distancia no es menos portadora de una exigencia de traducibilidad (Ubersetzbarkeit).

PALABRAS CLAVE: arqueología; represión; pervivencia.

\begin{abstract}
According to the first generation of the École des Annales, anachronism is "the most unforgivable of all sins". Benjamin, however, emphasized not only a certain inevitability of anachronism, but even its potentiality. His notion of the trace (Spur) emphasizes that which persists through different epochs, understood from an idea of survival (Nachleben), which gives rise to the archaeological figure of a past that interrupts the relation of the present to itself. Didi-Huberman's work, by giving channel to the intuitions pointed out by Benjamin, makes the power of anachronism the starting point for the conceptualization of a methodology in the field of history. The inactuality of the past is unfulfilled, prehistoric, archaeological, discontinuous and unconscious, whose distance is no less porteur of a demand for translatability (Ubersetzbarkeit).
\end{abstract}

KEYWORDS: archeology; repression; after life.

Si las reflexiones sobre el concepto de tiempo histórico en el siglo XX llevan la marca de un énfasis en la discontinuidad, en reacción contra el historicismo de cuño evolucionista del siglo anterior (Heidegger, Benjamin, Koselleck, Foucault, Hartog), donde la idea de época histórica, Zeitgeist, episteme, régimen de historicidad es portadora de una comprensión del tiempo como recortado por figuras discontinuas, condicionantes y totalizantes respecto de los esquemas de percepción y de la autocomprensión de los sujetos históricos, también puede observarse, incluso desde las primeras décadas del 
siglo XX (Warburg, Benjamin), pero con mayor fuerza y visibilidad desde inicios del siglo XXI (Didi-Huberman), un énfasis en la idea de un "anacronismo productivo", en tensión contra la idea de época histórica, y marcado por aquellos restos y pervivencias (Nachleben) que atraviesan las diferentes épocas, transgrediendo los contornos del Zeitgeist y generando una historia espectral, susceptible de interrumpir las épocas y de alterar sus pliegues de sentido. La idea de anacronismo se declina así según los siguientes ejes: a) contra los prejuicios positivistas y estructuralistas en contra de todo anacronismo; b) en relación con las ideas benjaminianas de actualización (Aktualisierung), huella (Spuren), umbral (Schwelle) y pervivencia (Nachleben); c) en relación con la noción de E. Bloch y de R. Koselleck de la simultaneidad de lo no simultáneo (Gleichzeitigkeit des Ungleichzeitigen) y con los trabajos de Didi-Huberman en torno de la idea warburgiana de pervivencia (Nachleben). Aquí insertamos la temática del anacronismo en relación con una prehistoria o protohistoria comprendidas como facies inconsciente de la historia, en el sentido de una capa invisibilizada en el presente por la tradición consagrada y por la ideología iluminista del progreso. Desde este punto de vista, según una sensibilidad prehistórica que echa raíces en la reivindicación del anacronismo, "no vamos al pasado, sino que el pasado viene a nosotros", al igual que viene a nosotros un contenido onírico reprimido en nuestra personalidad consciente.

\section{Inscripción post-hermenéutica del anacronismo}

Hay un relato de Kafka, denominado "Un mensaje imperial”, que Walter Benjamin escoge en sus emisiones radiales sobre el escritor checo, y que encabeza su ensayo de 1931 sobre Kafka titulado “Franz Kafka: la construcción de la Muralla China". ${ }^{1}$

Aquí, el protagonista principal es un mensajero que, en el momento de la agonía del emperador, es convocado por este último a su lecho de muerte. Rodeando al emperador están los notables de la corte que le abren paso, y el emperador dice al oído del mensajero una palabras que nadie puede oír, encomendándole a este último que transmita a un cierto destinatario, que lo espera en los confines del imperio, esas mismas palabras. $\mathrm{Y}$ al decirlo, el emperador, luego de hacerse repetir el mensaje al oído y de asentir, muere, ante la vista de una multitud congregada en los jardines del palacio imperial. Tan sólo para salir de la capital del imperio el mensajero debe atravesar innúmeros palacios y la dificultad se va multiplicando a medida que el mensajero intenta abrirse paso, de modo que rápidamente llega a la conclusión de que jamás podrá, en el lapso de su breve vida, hacer llegar el mensaje a su destinatario. Finalmente el autor sorprende con un final en el que el destinatario, en el otro

\footnotetext{
${ }^{1}$ Conferencia radiofónica de Walter Benjamin en la Radio de Frankfurt del 3 de julio de 1931 en la que el pensador alemán leyó, en el marco de un programa llamado "La hora de los libros" (que ocupaba el espacio horario de 18h05 a 18h30) este texto de Kafka llamado "Un mensaje imperial", que pertenece a la serie de relatos del autor checo encabezada por el cuento "Un médico de campo". Véase KAFKA, Franz. El mensaje imperial. In: Relatos completos. Buenos Aires: Losada, 2003. El estudio de Benjamin fue publicado por primera vez en 1969 en BENJAMIN, Walter. Über literatur. Frankfurt: Suhrkamp, 1969; y luego editado en la obra completa en Gesammelte Schriften. II. 2. Frankfurt: Suhrkamp, 1991; finalmente ha sido traducido y editado recientemente en español en BENJAMIN, Walter. Sobre Kafka: Textos, discusiones, apuntes. Buenos Aires: Eterna Cadencia, 2014.
} 
extremo del imperio chino, sueña sin embargo, desde su ventana, al mensajero del emperador con la caída de la tarde: “Du aber sitzt an Deinem Fenster und erträumst sie Dir, wenn der Abend kommt".2

Un final que quizá quiso sugerir una vinculación (Verschränkung) inconsciente entre un destinatario y un mensajero, una "simultaneidad de lo no simultáneo", para dos sujetos que, sin embargo, están separados espacialmente, de forma análoga a como, en los episodios de la pervivencia y del anacronismo que analizaremos más abajo, dos formas discontinuas se yuxtaponen en el tiempo. En cualquier caso, se da a pensar aquí, en relación con este relato, el problema - hoy llamado "post-hermenéutico" - ignorado por la tradición hermenéutica, y que es no tanto el problema de la interpretación, cuanto el de la transmisión material. Como señala Friedrich $\mathrm{Kittler}^{3}$, padre de la llamada post-hermenéutica, el dios Hermes primordialmente era mensajero y no intérprete. Para decirlo latamente, el mensajero tiene una función que precede y que es condición de posibilidad de la interpretación misma de un mensaje, y es su transmisión. El problema del quiebre de la transmisión está sugerido asimismo en otro relato del mismo Kafka, bastante más breve, titulado "El pueblo más cercano", y que precede inmediatamente "Un mensaje imperial": "Mi abuelo solía decir: - la vida es asombrosamente corta. Ahora, en el recuerdo, se me aparece tan de un solo golpe que apenas puedo comprender cómo, por ejemplo, un joven pueda decidirse a cabalgar hasta el pueblo más próximo sin temer que - posibles accidentes aparte - ya el tiempo mismo de la vida que transcurre normal, feliz, pueda no alcanzar ni por mucho para semejante cabalgata". ${ }^{4}$

Benjamin se refiere a este último relato en los materiales preparatorios a su conocido texto de 1934 titulado "Franz Kafka: en el décimo aniversario de su muerte". Aunque Benjamin declaró en 1931 que se rehusaba a interpretar "Un mensaje imperial", sin embargo, en este fragmento, que Schweppenhäuser añadió como "Montaje" en su edición de 1969 (Ms 237), Walter Benjamin acuñaba sugerentemente lo siguiente:

El pueblo más cercano" ["Das nächste Dorf”]. Brecht: esta historia es la contraparte [ein Gegenstück] de la de Aquiles y la tortuga. Alguien cualquiera no llegará jamás [nicht gerechnet] al pueblo más cercano si va componiendo la cabalgata [Ritt] a partir de las más pequeñas partes, sin contar los contratiempos. Entonces la vida es demasiado corta [zu kurz] para esta cabalgata. Pero el error (der Fehler) está aquí en ese "alguien" [im "einer"]. Pues así como la cabalgata se descompone en partes, así también el jinete [so auch der Reitende]. Y así como la unidad de la vida [Einheit des Lebens] está perdida, también lo está su brevedad [seine Kürze]. Que sea tan breve como quiera, esto nada cambia, pues llegará al pueblo otro distinto [ein anderer] del que se marcha a caballo. ${ }^{5}$

\footnotetext{
2 "Pero tú estás sentado a tu ventana, y te lo sueñas cuando cae la tarde". KAFKA, Franz, op. cit., p. 188.

${ }^{3}$ Véase KITTLER, Friedrich A. Gramophone, film, Typewriter. Stanford: Stanford University Press, 1999. Asimismo, véase SALE, Stephen e SALISBURY, Laure. Kittler Now. Cambridge: Polity Press, 2015.

${ }^{4}$ KAFKA, Franz, op. cit., p. 187.

${ }^{5}$ BENJAMIN, Walter. Sobre Kafka. Textos, discusiones, apuntes, op. cit., p. 203, y BENJAMIN, Walter. Gesammelte Schriften, op. cit., II.3, p. 1253.
} 
Se trata de comprender la Erfahrung (experiencia en sentido enfático) no ya como un hecho o vivencia de conciencia (Erlebnis) sino como un anudamiento descentrado de experiencias intersubjetivas, pervivientes, heterogéneas entre sí, y sin embargo articuladas o diseminadas en un reticulado de interacciones en el tiempo, que no están tanto en relación a la vivencia de un mismo yo, cuanto en relación a la traducción de diferentes lenguajes, o a la pervivencia de diferentes estratos, de diferentes desechos, ruinas e imágenes del pasado, ciertamente cargados de tiempo. En relación al pensamiento de Benjamin, nuestra experiencia del pasado se ordena en los planos de la pervivencia (Nachleben), del salvataje (Rettung) y de la redención (Erlösung), privando al polo de la muerte del carácter que asume en Heidegger en cuanto unidad del Dasein y fuente primordial de su autenticidad. Pero para abordar este desplazamiento es necesario transitar del plano hermenéutico-fenomenológico de la intencionalidad de la conciencia al plano antropológico, etnográfico y arqueológico del anacronismo. Es acompañados por pensadores como Aby Warburg, Georges Didi-Huberman, pero no menos por Ernst Bloch, Koselleck y Althusser, que puede elaborarse esta dimensión de lo perviviente en las figuras primero de lo anacrónico, lo survival, lo nachleben y después de la Ungleichzeitigkeit des Gleichzeitigen (la no simultaneidad de lo simultáneo).

\section{Traducir es umbralar (Schwellen). De las ruinas, destiempos e imágenes}

Georges Didi-Huberman, en L'image survivante: histoire de l'art et temps des fantômes selon Aby Warwurg', reflexionando sobre el etnólogo y antropólogo británico Edward Burnett Tylor (1832-1917), al que Didi Huberman consagra una sección del primer capítulo ${ }^{7}$, indica que Warburg tomó la expresión "survival" de Tylor, remitiendo a la capacidad para desterritorializar los campos del saber, introduciendo un uso arqueológico del anacronismo a través de un diferencial en los objetos mismos de la exploración antropológica y arqueológica. Didi-Huberman observa así que Tylor analiza las formas de las puntas de flechas talladas en México y descubre la supervivencia de dichas formas en las agujas y láminas fabricadas siglos después para la riña de gallos en torno a 1861, lo que marcaría "el juego vertiginoso del tiempo en la superficie presente de una cultura dada". Anacronismo y "survival" irrumpen así con Tylor en el discurso y en la práctica antropológica marcando un corte epistemológico con la aversión cientificista e historiográfica al anacronismo, subrayada por Didi-Huberman a propósito de Annales, cuando, según Didi-Huberman, el magistral Lucien Fèbvre definía al anacronismo "comme l'intrusion d'une époque dans une autre, illustrée par l'exemple surréaliste de César tué d'un coup de browning". 8

Este vértigo se expresa primeramente en la sensación poderosa de que el presente está tejido de pasados múltiples. La complejidad horizontal de lo

\footnotetext{
${ }^{6}$ DIDI-HUBERMAN, Georges. L'image survivante: histoire de l'art et temps des fantômes selon Aby Warburg. Paris: Minuit, 2002.

${ }^{7}$ Idem, ibidem, op. cit., p. 51-71.

8 "Como la intrusión de una época en otra, ilustrado por el ejemplo surrealista de César asesinado por el disparo de una Browning". DIDI-HUBERMAN, Georges. Devant le temps. Paris: Minuit, 2000, p. 29 (traducción nuestra).
} 
que ve el antropólogo o el etnólogo concierne a su vez la complejidad vertical paradigmática del tiempo.

Progreso, decadencia, supervivencia, renacimiento, modificación (progress, degradation, survival, revival, modification) son a la vez formas según las cuales se ligan las partes de la red compleja de la civilización. Basta una mirada sobre los detalles vulgares [trivial details] de nuestra vida cotidiana para conducirnos a distinguir en qué medida nosotros no hacemos sino transmitir y modificar la herencia de los siglos anteriores. Aquel quien sabe que su propio tiempo es incapaz de darse cuenta de lo que él mira solamente cuando mira alrededor de su pieza. ${ }^{9}$

Didi-Huberman observa que aquí la supervivencia aparece bajo la forma de marcas, huellas, impresiones, empreintes. Decir que el presente es portador de la marca de múltiples pasados es decir sobre todo la indestructibilidad de una marca - del o de los tiempos - sobre las formas mismas de nuestra vida actual. Tylor hablará de este modo de la tenacidad de las supervivencias (strength of these survivals) por el cual "las viejas costumbres conservan sus raíces en el suelo alterado por una nueva cultura". Warburg hablará aquí de la "tenacidad de formas antiguas en la larga duración de la historia del arte occidental". ${ }^{10} \mathrm{La}$ tenacidad de las supervivencias, su potencia, aparece de este modo en lo tenue de las cosas minúsculas, superfluas, irrisorias, anormales. Es en el síntoma recurrente y en el juego, en la patología de la lengua y en el inconsciente de las formas que yace la supervivencia como tal.

En este sentido, el trabajo de Didi-Huberman, dando cauce a las intuiciones señaladas por Benjamin, Warburg y Carl Einstein, hace de la inevitabilidad de la figura del anacronismo el punto de partida para la conceptualización de una metodología arqueológica efectiva en el ámbito de la historia. Radicalizado, el anacronismo se presenta de modo positivo, con un potencial productivo inherente, e incluso como la condición de posibilidad misma de la consideración histórica. La historia del arte puede y debe ser concebida de antemano como una disciplina anacrónica: más precisamente, como una arqueología del anacronismo. ${ }^{11}$ Movimiento de radicalización, en primer lugar, porque así la figura del anacronismo nos enfrenta a la sospecha de que "los contemporáneos a menudo no se comprenden mejor que los individuos separados en el tiempo: el anacronismo atraviesa todas las contemporaneidades. No existe - casi - la concordancia entre los tiempos". ${ }^{12}$ Esta inevitabilidad, que parece constituir la fatalidad del anacronismo, da lugar a un segundo movimiento de radicalización: trastocado en necesidad del anacronismo para el ejercicio mismo del historiador, el límite se revela como fuente de "riqueza"13; la figura se torna así la condición misma del enraizamiento arqueológico. En segundo lugar, a partir de un concepto benjaminiano no genético de "origen", luego enriquecido desde las ideas benjaminianas de "tomar la historia a contrapelo", el anacronismo o actualización (Aktualisierung) pasa a ser una poten-

\footnotetext{
${ }_{9}^{9}$ TYLOR, Edward Burnett. Primitive culture (1871), apud DIDI-HUBERMAN, Georges, op. cit., p. 56.

${ }^{10} \mathrm{Idem}$.

${ }^{11}$ DIDI-HUBERMAN, Georges. Ante el tiempo: historia del arte y anacronismo de las imágenes. Buenos Aires: Adriana Hidalgo, 2015, p. 62.

${ }^{12}$ Idem, ibidem, p. 38.

${ }^{13} \mathrm{Idem}$.
} 
cia inherente a los objetos históricos mismos, cristalizada en la imagen dialéctica. En este sentido, en efecto, la Aktualisierung supuso en Benjamin el rechazo de la determinación genética de la idea de origen, entendido como figura causal lineal (Entstehung), a la que Benjamin le contrapuso una idea de origen como fenómeno primordial (Ur-Phänomen) y actualidad esencial, es decir, como todavía siendo y permaneciendo (Ursprung) $)^{14}$, una figura que deviene en una fuerza que hace a la pervivencia (Nachleben) de un pasado a la vez latente y en instancia de actualización. Se trata de la pervivencia del pasado mismo en su anacronismo esencial como potencia de irrupción en el presente (Aktualisierung). Lejos de limitarse a ser la prohibición fundacional de la metodología historiográfica, el anacronismo deviene en un rasgo ontológico que hace posible la historiografía misma.

Mientras que la segunda mitad del siglo XX nos ha familiarizado con las gramáticas, las estructuras y los a priori históricos, desde Binswanger a Foucault y de Levi-Strauss a Kuhn, el redescubrimiento tardío de Benjamin, por su parte, nos lleva en cambio a pensar las huellas, la supervivencia, el $\mathrm{Na}$ chleben. El Nachleben y la huella invocan una experiencia que no es meramente una experiencia dentro de los límites, sino aquello que Benjamin denomina una "experiencia de umbral". Las nociones de umbral - Schwelle - y de límite - Grenzen- son diferentes en Walter Benjamin. Permítasenos, en este sentido, reproducir un fragmento extraído del Passagen-Werk:

Hay que distinguir con toda claridad [schärfstenszuunterscheiden] el umbral [Schwelle] del límite [Grenze]. El umbral es una zona [Zone]. Y ciertamente una zona de transición [Überganges]. El término "umbralar" [schwellen] implica cambio [Wandel], transición [Übergang], escape [Fliehen]. Y la etimología no ha de pasar por alto estos significados. Por otra parte, es necesario indagar el contexto directamente arquitectónico [sic] [tektonischen/ tectónico] que ha dado a esta palabra su significado. Nos hemos vuelto muy pobres en experiencias de umbral [wir sind sehr arm an Schwellen erfahrung engeworden]. Conciliar el sueño [Das "einschlafen"] es quizá la única que nos ha quedado. Pero al igual que el mundo figurativo de los sueños [Gestalten Welt des Traumes] sobrepasa el umbral, también lo hace el sube y baja [unterhaltung] del entretenimiento y del intercambio sexual del amor [Geschlechterwandel der Liebe]. La puerta monumental, que transforma a quien la cruza, se desarrolló a partir del ámbito de la experiencia del umbral [Erfahrungskreise der Schwelle]. El arco de triunfo romano convierte en triunfador al general que regresa. ${ }^{15}$

\section{El angel de la (pre)historia: historia natural y “(des)esperanza en el pasado"}

Si lo "no-humano" (Unmensch) ${ }^{16}$ encuentra en la antropología histórica de Benjamin un lugar central como expression de una dialéctica entre la histo-

\footnotetext{
${ }^{14}$ BENJAMIN, Walter. El origen del Trauerspiel alemán. In: Obras: libro I, v. 1. Madrid: Abada, 2006, p. 243.

${ }^{15}$ BENJAMIN, Walter. Libro de los pasajes. Madri: Akal, 2005, p. 850; y por el original alemán, BENJAMIN, Walter. Das Passagen-Werk. Frankfurt: Suhrkamp Verlag, [Mํ, 25], 1982, p. 1025.

${ }_{16}$ Véase esta expresión de Unmensch - literalmente "no humano" - como título de la tercera y última sección del ensayo de Walter Benjamin sobre Karl Kraus. BENJAMIN, Walter. Gesammelte Schriften, II.1. Frankfurt /Main:Suhrkamp, 1991, p. 354-367, y su traducción en Obras, II.1, Madrid: Abada, 2007, 363-376, con el término "monstruo", que es, a nuestro criterio, traducción inapropiada, no porque desconozcamos a los monstruos en la extensión de la noción de lo no-humano, sino porque "lo monstruo" no caracteriza a la expresión benjaminiana Unmensch en toda su riqueza. Véase sobre este punto DI PEGO, Anabella. Hacia una política de
} 
ria y la naturaleza orgánica e inorgánica, aquí nos focalizamos específicamente en el personaje conceptual del "Ángel de la historia" (Engel der Geschichte), inscripto en la célebre tesis 9 del ensayo de Benjamin sobre el concepto de historia $(1940)^{17}$, como una figura no humana que encarna a la vez una mirada suprahistórica sobre el pasado humano y una mirada proto o pre-histórica sobre la historia natural. El ángel es no-humano y, sin embargo, por no-humana que fuera su figura, es llamado aquí literalmente "Ángel de la Historia"18, es decir, de todo lo humano en cuanto que es histórico. ¿Cómo interactúa aquí lo no-humano (Unmensch) con lo humano? El rasgo no humano se revela por un lado en el tipo de mirada de este personaje, que no es la mirada del actor histórico involucrado en su acción, ni tampoco la mirada del historiador involucrada en un pasado particular, sino la mirada que sobrevuela la totalidad del pasado como en en una sola instantánea. En relación al agente histórico, si consideramos que existencialmente - como señala Heidegger en Ser y tiempo el agente, es decir, el Dasein humano, está orientado por el futuro y por su proyecto (Entwurf), este Ángel de la historia no presta ninguna atención al futuro, sino que solamente lo padece en cuanto fuerza exterior e involuntaria que lo propulsa a pesar suyo como una tempestad, mientras mantiene toda su atención clavada en el pasado. Ciertamente el historiador también mira el pasado mientras el tiempo lo empuja al futuro, pero es siempre un pasado en particular, como bien señala Aristóteles en su Poética, al oponer el poeta, que mira lo universal, y el historiador, que mira siempre - podríamos aquí añadir idiográficamente - un pasado singular.

¿Es acaso la mirada de este Ángel de la historia semejante al Búho de Hegel que, en el prefacio a su filosofía del derecho, mira la época ya pasada en un solo cuadro? El ángel de Benjamin mira todo el pasado como en una instantánea. En este sentido, hay algo totalizante en su mirada, porque allí donde el actor y el historiador, es decir los humanos, "vemos cadenas de sucesos" (Kette von Begebenheiten), el Ángel de la Historia ve una única catastrophe (einzige Katastrophe), que "es una montaña de ruinas que trepa hasta el cielo". Se podría decir así que su mirada no-humana es suprahistórica por excelencia. Sin embargo la mirada suprahistórica del Búho hegeliano es una mirada de comprensión, de reconciliación con el pasado, por vía de conocimiento y saber, que vuelve a unir los hilos del tiempo en el reconocimiento de la razón y del absoluto en la historia. En cambio, la mirada del Ángel de la historia benjaminiano, es una mirada desesperada, traumatizada. Porque este Ángel mira una catastrophe y al mismo tiempo no puede componerla ni repararla en nin-

\footnotetext{
lo no-humano (Unmensch): Walter Benjamin y Paul Scheerbart. Anthropology \& Materialism: A Journal of Social Research, n. especial “Walter Benjamin y los materiales antropológicos”, 2021 (en prensa).

${ }^{17}$ BENJAMIN, Walter, Über den Begriff der Geschichte. In: I.2, p. 697 e 698, trad. en OYARZÚN, Pablo, La dialéctica en suspenso: fragmentos sobre la historia. Santiago de Chile: Arcis, 1995, p. 53 e 54.

${ }^{18} \mathrm{Si}$ el Ángel de la historia (Engel der Geschichte) es introducido por Benjamin en la tesis 9 por analogía con el personaje del cuadro Angelus Novus, de Paul Klee, que Benjamin había adquirido en 1921, la figura del cuadro de Klee no debe confundirse con el Ángel de la historia, como bien señala Sigrid Weigel, ya que el último es en rigor una imagen de pensamiento (Denkbild), con rasgos propios que no pueden atribuirse sin más al primero, en particular su mirada y fijación azorada en el pasado como una instantánea que abarca ruina sobre ruina hasta el cielo, mientras que el personaje es empujado involuntariamente por una tempestad llamada "progreso" que sopla desde el paraíso y lo arrastra inexorablemente hacia el futuro, al que da la espalda. Véase WEIGEL, Sigrid. Imágenes de pensamiento: una relectura del "Ángel de la Historia". In: Cuerpo, imagen y espacio en Walter Benjamin. Buenos Aires: Paidós, 1999.
} 
guna comprensión ni redención históricas. Bien quisiera, el Ángel de la Historia benjaminiano reparar la unidad destrozada y aliviar y redimir a los muertos, volviendo a juntar los pedazos rotos, pero a diferencia del Búho de Minerva de Hegel, no puede, porque la tempestad, que no es otra que la del progreso, le impide detenerse. El ángel no puede en cierto sentido volver a reconciliar el pasado dentro de la tradición. Lo que prevalece en su mirada es, por un lado, lo traumático, en su falta de reconciliación, y lo alegórico, en su falta de representación. Eso permite pensar su mirada bajo la figura de cierta imposibilidad del duelo y, al mismo tiempo, como una forma del retorno psicoanalítico de lo reprimido, en cuanto agonalidad irreconciliable entre las fuerzas seculares del progreso y las necesidades terapéuticas de la memoria testimonial. En este sentido, el ángel de la historia es también un Ángel testigo de la memoria traumática, que no puede volver a encerrar dentro de un sentido ni de una representación el pasado roto. Hay un abismo entre esta mirada nohumana, que Theodor Adorno llamó Medúsea, y la mirada entusiasmada del espectador kantiano, o del sabio y romantico Búho de Minerva hegeliano, que mira el episodio histórico con el entusiasmo de lo sublime o con la melancolía resignada de una reconciliación intelectual con el pasado. Tampoco es la mirada del Ángel de la historia la mirada suprahistórica del frío historiador criticado por Nietzsche, que mira el pasado con la indiferencia relativista de quien sólo contempla los pasados como habitaciones de un museo, ni incluso el hilo narrativo arendtiano, que ve el pasado bajo el prisma del sentido narrativo posterior de la revelación, en el resplandor histórico de lo público.

La originalidad del ángel benjaminiano es que no calza con ninguna de estas figuras familiares en la reflexión filosófica sobre la historia. Lo que por ende importará aquí es el carácter distópico, anacrónico, disimultáneo y anacrónico de la mirada de este Ángel de la historia; uno podría decir, es una mirada post-histórica, porque ve en una instantánea la totalidad de la historia como historia natural, es decir, su facies hipocrática como paisaje primordial petrificado. Y cómo no evocar aquel célebre pasaje del Trauerspiel benjaminiano, donde lo alegórico se une a la figura de la historia natural, en la imagen ya no humana de la calavera, pensada como alegoría y punto de fuga:

En la alegoría la facies hippocratica de la historia se ofrece a los ojos del observador como paisaje primordial petrificado. Todo lo que la historia desde el principio tiene de intempestivo, de doloroso, de fallido, se plama en un rostro; o mejor dicho: en una calavera. $Y$, si bien es cierto que ésta carece de toda libertad "simbólica" de expresión, de toda armonía formal clásica, de todo rasgo humano, sin embargo, en esta figura suya (la más sujeta a la naturaleza) se expresa plenamente y como enigma, no sólo la condición de la existencia humana en general, sino también la historicidad biográfica de un individuo. Tal es el núcleo de la visión alegórica, de la exposición barroca y secular de la historia en cuanto historia de los padecimientos del mundo, el cual sólo es significativo en las fases de su decadencia. A mayor significación, mayor sujeción a la muerte, pues es la muerte la que excava más profundamente la abrupta línea de demarcación entra la physis y la significación. Pero si la naturaleza ha estado desde siempre sujeta a la muerte, entonces desde siempre ha sido también alegórica. ${ }^{19}$

${ }^{19}$ BENJAMIN, Walter. El origen del drama barroco alemán. Madrid: Taurus, 1990, p. 159. 
El término "historia natural" (Naturgeschichte), que Benjamin utiliza repetidamente después de haberlo introducido a mediados de la década de 1920 en su Trauerspiel (1928), parece un oxímoron, al unir en un mismo significante dos denominaciones que la corriente predominante de la tradición filosófica occidental siempre ha querido separar, a saber, "naturaliza", como ámbito cosmológico de una fenomenalidad cerrada sobre sí misma, bajo una ley idéntica que escapa al hombre, e "historia", como dominio de las prácticas interhumanas y de los acontecimientos que de ellas se derivan, cuya marca distintiva es la emergencia de lo cualitativamente nuevo, en términos de praxis, interacción, iniciativa o "nacimiento". Sin embargo, antes del siglo XX, los naturalistas habían utilizado ampliamente el término "historia natural". Francis Bacon, en particular, la introdujo en su Novum Organon para denominar el registro y la taxonomía de los hechos particulares e idiosincrásicos de la naturaleza orgánica e inorgánica, ya sea de la tierra, del cielo o de la vida en todos sus aspectos. Después de Bacon, el mismo uso se encuentra en Newton, Gautier d'Agoty, Buffon e incluso Goethe, que clasifica sus estudios sobre la metamorfosis de las plantas bajo este nombre. El museo parisino del Jardin des Plantes, en este sentido, fue rebautizado en el siglo XVIII como "Museum d'histoire naturelle" por iniciativa de Buffon, nombre que más tarde serviría de modelo para la museografía de plantas y animales. Sin embargo, en todos estos usos prebenjaminianos, el término siempre se utilizó dentro de una clasificación de las disciplinas naturales, para distinguir entre la "filosofía natural" o "ciencia natural", centrada en las leyes universales de la naturaleza, y la "historia natural", orientada por el registro de fenómenos naturales particulares. Este uso no abarca los fenómenos de la cultura y de la historia humana, mantenidos radicalmente separados de la "historia natural". Sin embargo, para Benjamin a partir de 1925 y para Adorno a partir de 1932, la Naturgeschichte se convierte, más allá del archivo del movimiento y las mutaciones de la naturaleza, en un rasgo ontológico de la propia historia humana, como obsolescencia y caducidad y, por tanto, en una forma de retorno de la naturaleza a la historia: su facies hippocratica, como lo expresa Benjamin en su Trauerspiel, en el pasaje que acabamos de reproducer supra. ${ }^{20}$

Desde el momento en que la Naturgeschichte se convierte así en una noción para elpensamiento de la historia, la noción de Naturgeschichte adquirirá nuevos rasgos en la filosofía:

(a) como un pensamiento de caducidad y decadencia en la escala de la historia; (b) como un pensamiento de reificación y de lo que Lukàcs llamó "Segunda Naturaleza" para hablar de los procesos de subjetivación y reproducción cultural en el capitalismo moderno (Lukàcs, 1916; Adorno, 1932); (c) como "proto-história" (Urgeschichte) de la modernidad, refiriéndose no a un tiempo antediluviano sino al ámbito "arcaico" más reciente, es decir, lo suranné. La protohistoria, constituida por las ruinas, los residuos y los fósiles, que el capitalismo industrial moderno a la vez produce e invisibiliza en su frenética carrera por el "progresso", encierra sin embargo una dialéctica entre la represión (Verdrängung), que comparamos con la del inconsciente freudiano, y el despertar (erwachen), no exenta de un potencial de interrupción, redención

${ }^{20}$ Para la versión alemana, véase BENJAMIN, Walter. Gesammelte Schriften, op. cit., 1.1, p. 343. 
y mesianismo. Estos últimos rasgos, bien propios de la Naturgeschichte en el último Benjamin, están ausentes de la noción adorniana de Naturgeschichte, focalizada solamente en la decadencia y en la caducidad de la historia humana. Por ende, si es menester identificar los niveles de significado de la noción de historia natural en la obra de Benjamin y Adorno, considerando los aspectos que son comunes y los que distinguen los usos de los dos autores alemanes, en particular para pensar la relación entre historia natural e historia, asimismo resulta indispensable indicar y abrir las dimensiones contemporáneas de la noción de historia natural para pensar en las relaciones entre lo humano y lo no humano, en relación con la crisis de los fundamentos humanistas de la historia. El diálogo con las filosofías francesa y anglosajona de la segunda mitad del siglo XX se convierte aquí en un nodo decisivo y en un prometedor retorno a la tradición de la Naturgeschichte en el pensamiento crítico alemán.

Artigo recebido em 13 de outubro de 2021. Aprovado em 30 de novembro de 2021. 